\title{
Correction to: The novel multi-swarm coyote optimization algorithm for automatic skin lesion segmentation
}

\author{
Gehad Ismail Sayed ${ }^{1}$. Ghada Khoriba ${ }^{2} \cdot$ Mohamed H. Haggag ${ }^{2}$
}

๑) Springer-Verlag GmbH Germany, part of Springer Nature 2020

\section{Correction to: Evolutionary Intelligence}

https://doi.org/10.1007/s12065-020-00450-4

Unfortunately, table 8 was published incorrectly in the online published article. The correct Table 8 is given below.

Publisher's Note Springer Nature remains neutral with regard to The original article has been corrected.

The original article can be found online at https://doi.org/10.1007/ s12065-020-00450-4.

Gehad Ismail Sayed

GehadIsmail_FCI@yahoo.com

1 Faculty of Computers and Information, Cairo University, Giza, Egypt

2 Faculty of Computers and Information, Helwan University, Helwan, Egypt 
Table 8 Multi-level thresholding segmentation results with histogram with an indicator of the optimal thresholds values for different threshold values $\mathrm{k}$ of IMD008, IMD015 and IMD040

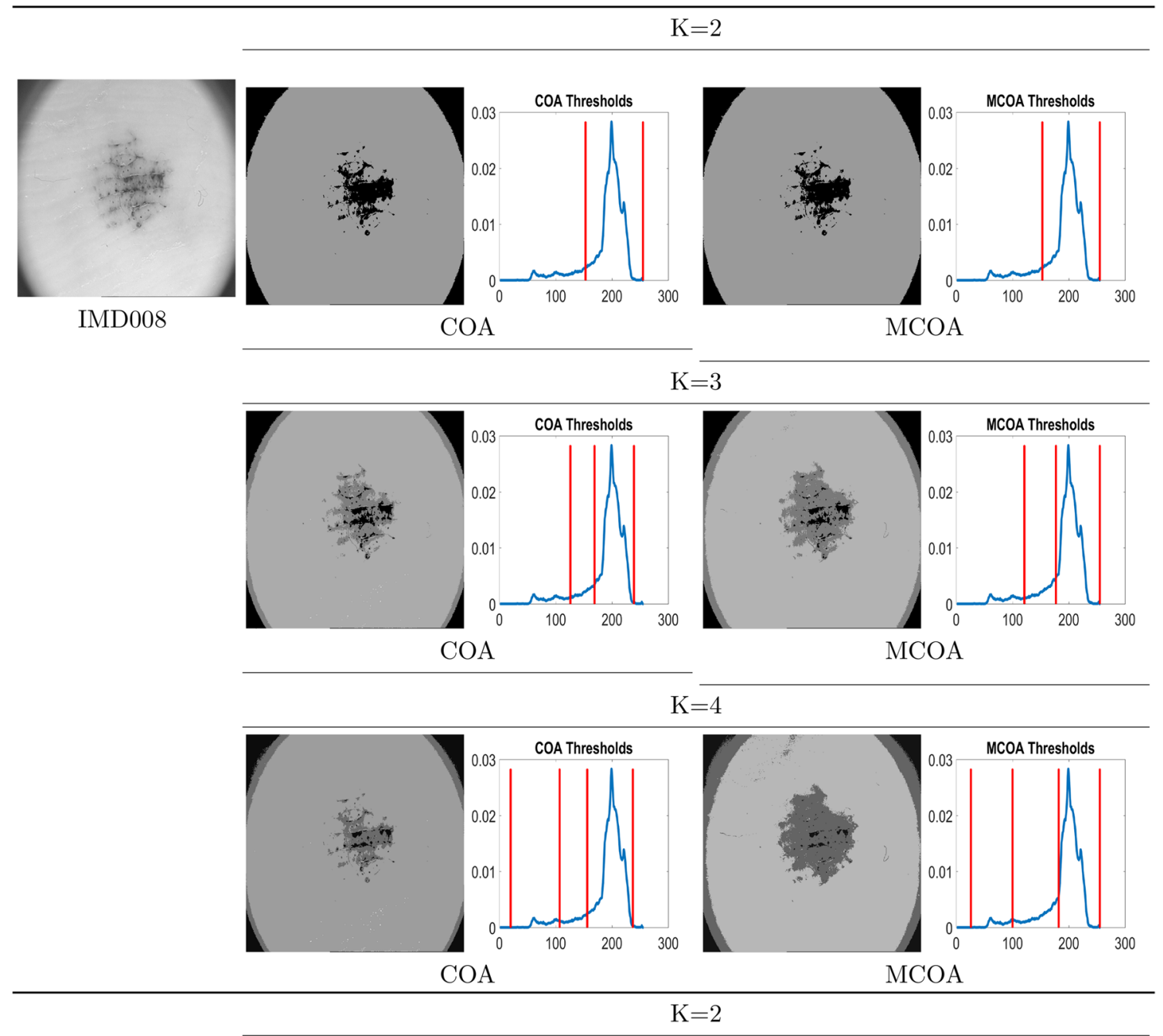

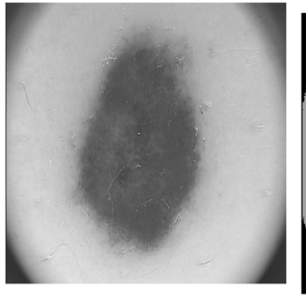

IMD015

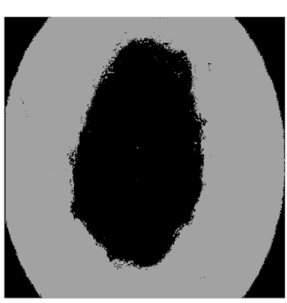

$\mathrm{COA}$

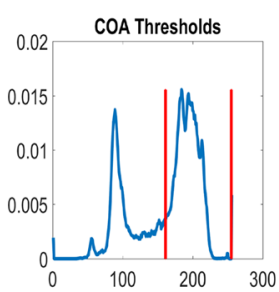

300

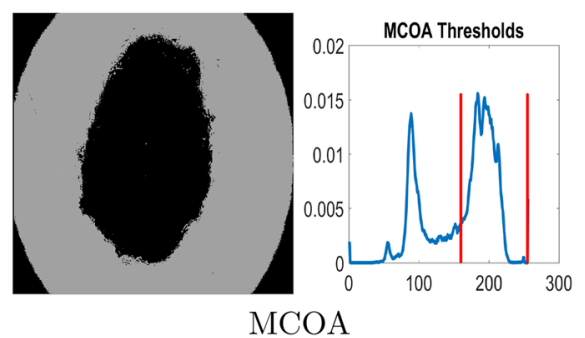


Table 8 (continued)
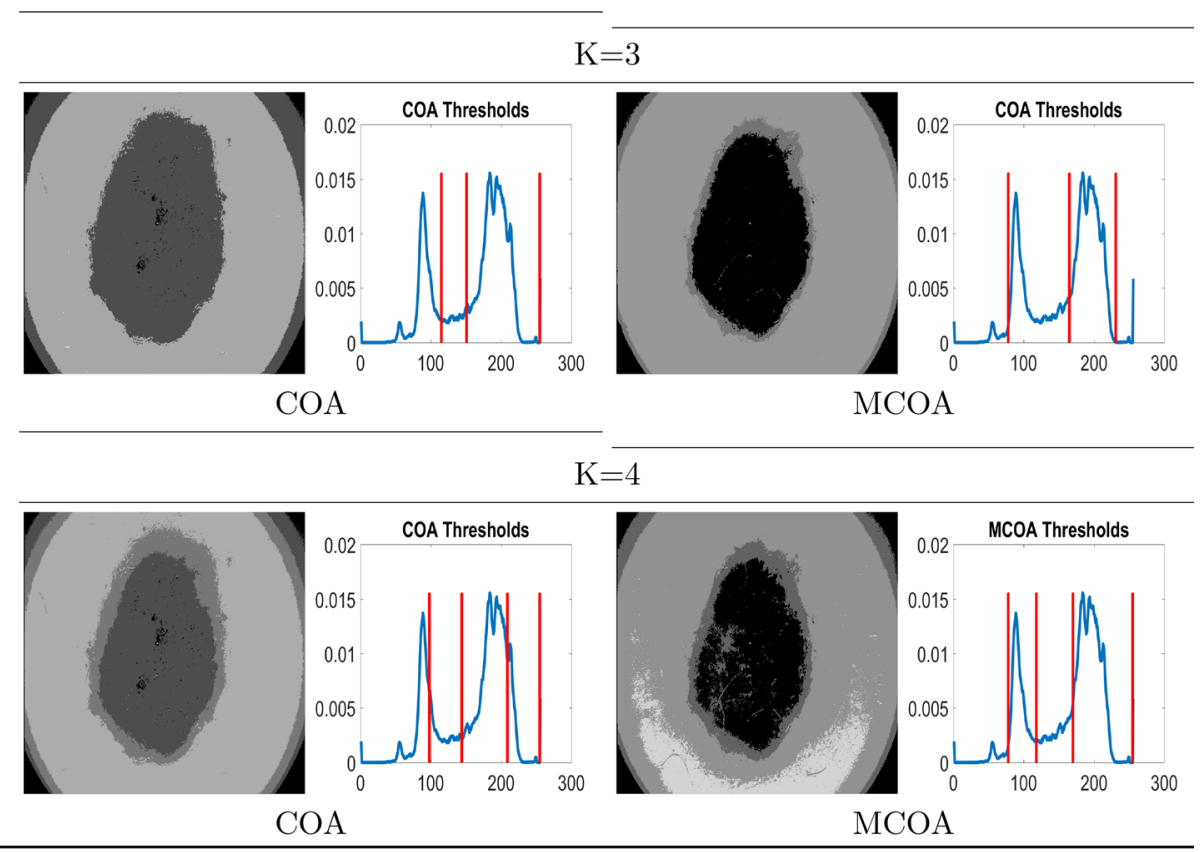

$K=2$

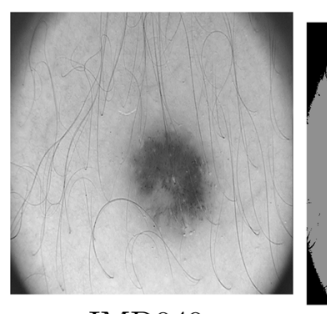

IMD040

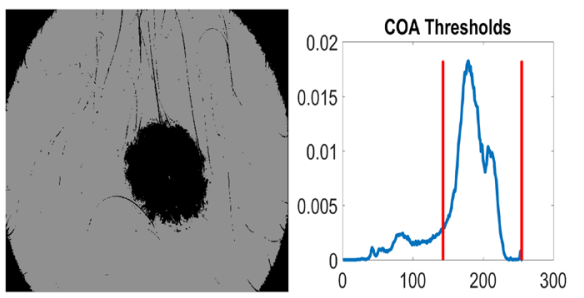

$\mathrm{COA}$

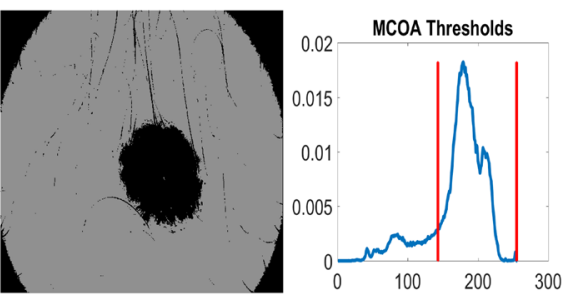

MCOA
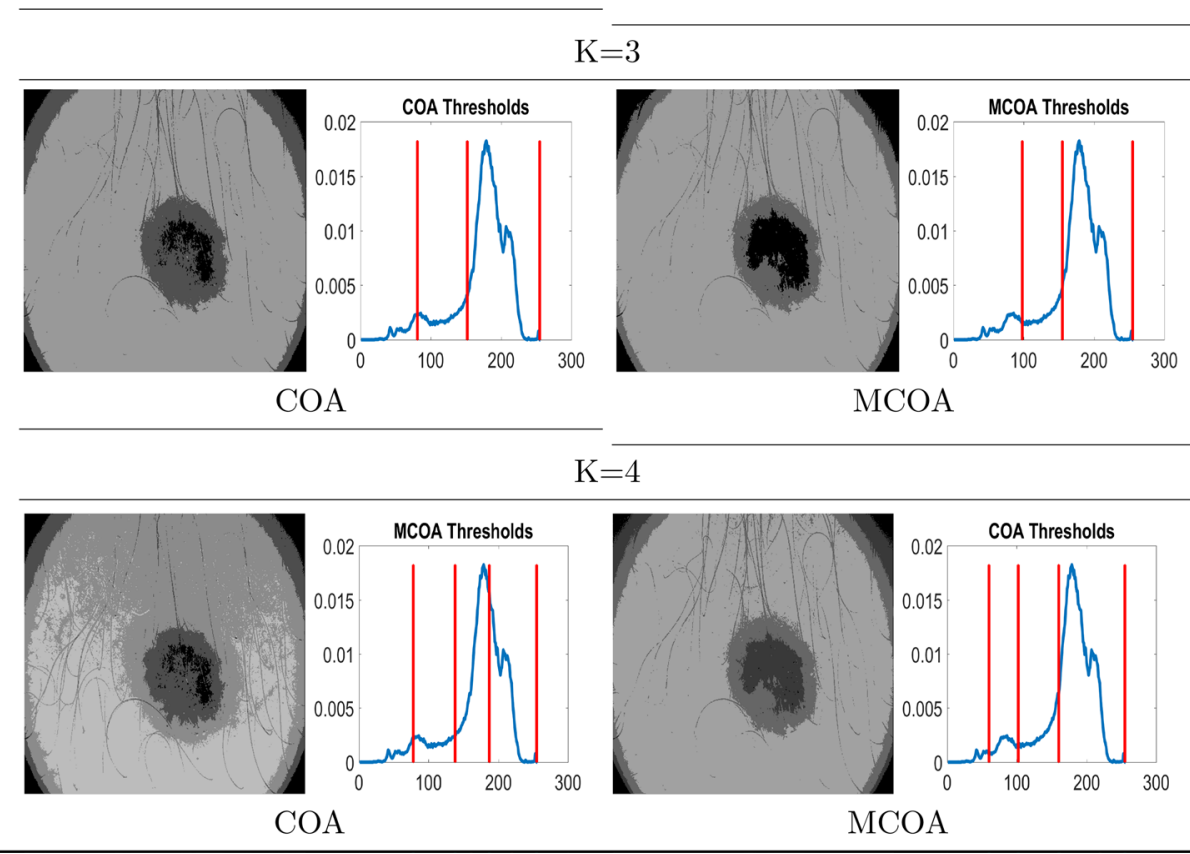